\title{
Design and Synthesis of Metal Complexes of (2E)-2-[(2E)-3- Phenylprop-2-en-1-ylidene]hydrazinecarbothioamide and Their Photocatalytic Degradation of Methylene Blue
}

\author{
P. Murali Krishna, ${ }^{1}$ N. B. Gopal Reddy, ${ }^{1}$ Nagaraju Kottam, ${ }^{1}$ \\ B. C. Yallur, ${ }^{1}$ and Hussain Reddy Katreddi ${ }^{2}$ \\ ${ }^{1}$ Department of Chemistry, M. S. Ramaiah Institute of Technology, Bangalore 560 054, India \\ ${ }^{2}$ Department of Chemistry, Sri Krishnadevaraya University, Anantapur 515 006, India \\ Correspondence should be addressed to P. Murali Krishna; muralikp21@gmail.com and Nagaraju Kottam; knrmsr@gmail.com
}

Received 1 August 2013; Accepted 20 August 2013

Academic Editors: A. Hursthouse and C. Zhang

Copyright ( $) 2013$ P. Murali Krishna et al. This is an open access article distributed under the Creative Commons Attribution License, which permits unrestricted use, distribution, and reproduction in any medium, provided the original work is properly cited.

\begin{abstract}
The photocatalytic degradation has been considered to be an efficient process for the degradation of organic pollutants, which are present in the effluents released by industries. The photocatalytic bleaching of cationic dye methylene blue was carried out spectrometrically on irradiation of UV light using $\mathrm{Cu}(\mathrm{II}), \mathrm{Ni}(\mathrm{II})$, and $\mathrm{Co}(\mathrm{II})$ complexes of (2E)-2-[(2E)-3-phenylprop-2-en-1ylidene]hydrazinecarbothioamide (HL). The effects of $\mathrm{pH}$ and metal ion were studied on the efficiency of the reaction. $\mathrm{Cu}(\mathrm{II})$ complex shows better catalytic activity and the highest percentage degradation $(\sim 88.8 \%)$ of methylene blue was observed at $\mathrm{pH} 12$. A tentative mechanism has also been proposed for the photocatalytic degradation of methylene blue.
\end{abstract}

\section{Introduction}

Water pollution can be defined as any physical, chemical, or biological alteration in water quality that affects living organisms. Industries and human communities are the main sources, which mainly caused the pollution of surface waters like rivers, lakes, and seas [1]. Dye is a common contaminant or pollutant compound that can be easily found in wastewater [2]. Many industries are using dyes to colour their products, and they consume substantial volumes of water. The presence of small amounts of dyes in water is highly visible and undesirable [3]. Dyes are mainly applied in textile manufacturing, leather tanning, paper production, and food technology industries. The discharge of the major constituent of pollutants in wastewater into water sources from textile and other industries affects water quality including temperature, turbidity, $\mathrm{pH}$, alkalinity, acidity $\mathrm{BOD}, \mathrm{COD}$, and colour. The discharge of those coloured wastewaters in the ecosystems causes serious environmental problems like aesthetic pollution and eutrophication and can originate dangerous by-products through oxidation, hydrolysis, or other chemical reactions in the wastewater phase $[4,5]$. Therefore, the wastewater treatment is desirable to overcome this problem. Methylene blue is a kind of cationic dye (basic dye) containing heterocyclic aromatic chemical compound with the molecular formula $\mathrm{C}_{16} \mathrm{H}_{18} \mathrm{~N}_{3} \mathrm{SCl}$. This dye is generally classified as a basic dye and cationic species due to the presence of positively charged quaternary nitrogen atoms (as $\mathrm{NR}_{3}{ }^{+}$or $=\mathrm{NR}_{2}{ }^{+}$). These groups enhance the solubility of dye in water due to their ionic characteristic [6]. Several methods of treatment of effluents have been undertaken from time to time; the most common methods are chemical precipitation and biological methods. However, these methods suffer from many disadvantages, but photocatalytic degradation seems to be the most promising advanced oxidation processes (AOPs) since it is of low cost and less time consuming [7] and is based on the generation of hydroxyl radicals $[8,9]$, which can be used for nonspecific oxidation of a wide range of organic compounds. AOPs include the classical Fenton reaction as well as its modifications (e.g., light assisted Fenton oxidation 


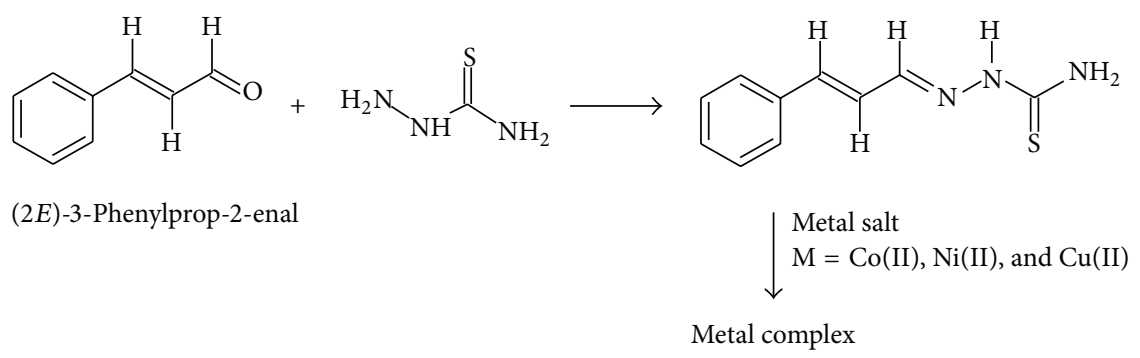

Scheme 1: Synthesis of ligand and its complexes.

or ferrioxalate-photo Fenton oxidation) as well as $\mathrm{H}_{2} \mathrm{O}_{2} / \mathrm{UV}$ or ozonization [10-14]. However, Fenton's reagent can work only under acidic conditions ( $\mathrm{pH} 2-4)$, and some dyes are not completely decomposed $[15,16]$. Another set of AOP reactions makes use of transition metal ions (mostly $\mathrm{Cu}$ ) in combination with ligand molecules for the decomposition of hydrogen peroxide and the resulting production of hydroxyl radicals. The main advantage of such systems is the broad substrate specificity and the ability to perform at $\mathrm{pH}$ 3-9 $[16,17]$. Copper(II) complex systems have been used for the degradation of lignin [18], polycyclic aromatic hydrocarbons [19], and synthetic dyes [17, 20]. Hence, researchers are keen to search for a low-molecular weight ligand with high decolonization efficiency to be used in these reactions and to demonstrate the involvement of hydroxyl radicals in the decolonization reaction. The literature survey reveals that the metal complexes used for the degradation of dyes are nitrogen and oxygen containing copper complexes, and we are not aware of the literature about the usage of copper, nickel, and cobalt complexes containing sulphur and nitrogen as donor atoms. Herein, we report for the first time the results of our attempts to reduce/remove the methylene blue dye from sewage water using copper(II), nickel(II), and cobalt(II) complexes of (2E)-2-[(2E)-3-phenylprop-2-en-1ylidene]hydrazinecarbothioamide.

\section{Experimental}

2.1. Materials and Methods. All the reagents used were of analytical grade and used without further purification. Thiosemicarbazide and (2E)-3-phenylprop-2-enal were purchased from Sigma-Aldrich, Bangalore, India. Metal chlorides were purchased from Merck. Methylene blue (MB) was purchased from S D Fine Chem. Limited, Mumbai. All the solvents were used as supplied without further purification.

The ligands and complexes were analyzed for their C, $\mathrm{H}$, and $\mathrm{N}$ estimated on Perkin-Elmer $2400 \mathrm{CHN}$ elemental analyser. Infrared spectra were recorded in the 4000$400 \mathrm{~cm}^{-1}$ region (KBr disc) on a Nicolet protege $460 \mathrm{FT}-\mathrm{IR}$ spectrophotometer. The molar conductance $\left(10^{-3}\right)$ in DMF at $30 \pm 2^{\circ} \mathrm{C}$ was measured with a CC180 model (ELICO) direct reading conductivity bridge. Magnetic susceptibility measurements were made for all the complexes at $298 \mathrm{~K}$ using magnetic susceptibility balance (Sherwood Scientific, Cambridge, UK). High purity hydrated copper sulphate was used as a standard.

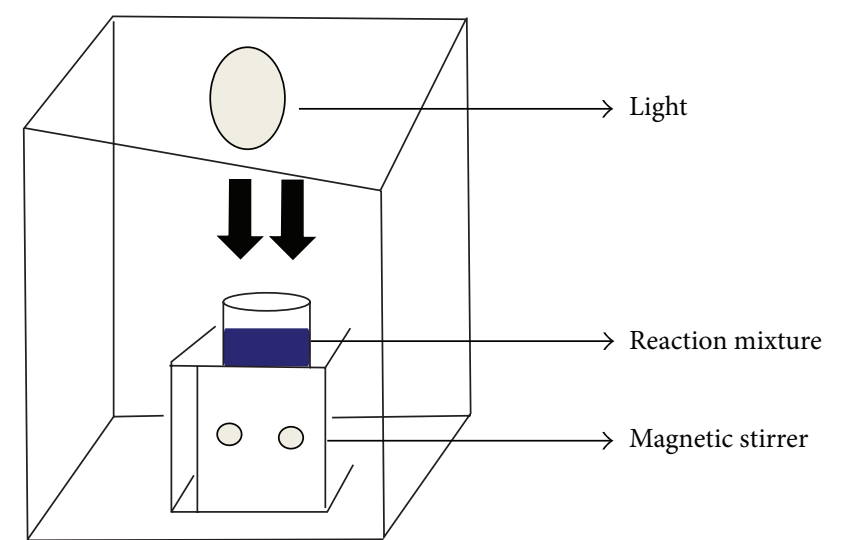

FIgURE 1: Photocatalytic experimental setup.

2.2. Preparations of Ligand $(H L)$. The ligand was prepared by condensing thiosemicarbazide with (2E)-3-phenylprop2-enal by following the general procedure [21] given in Scheme 1 . To a $5 \%$ glacial acetic acids in water solution $(20 \mathrm{~mL})$ of thiosemicarbazide $(1 \mathrm{~mol})$, add ethanolic solution $(10 \mathrm{~mL})$ of (2E)-3-phenylprop-2-enal $(1 \mathrm{~mol})$ the mixture was refluxed for 2-3 hrs. The crystalline product was collected by filtration, washed several times with hot water, and dried. All the thiosemicarbazones were recrystallised from ethanol.

2.3. Preparation of Complexes. The synthesis of complexes was based on the general procedure. To a solution of Ligand (HL) in $15 \mathrm{~mL}$ of methanol, appropriate metal chlorides were added and refluxed for $3 \mathrm{hrs}$. The formed precipitate was then filtered off, washed with cold methanol, and dried.

2.4. Photocatalytic Activity. A photocatalytic activity of metal complexes (MC) on the degradation of methylene blue (MB) in water was examined with and without UV-light (Figure 1). A $300 \mathrm{~W}$ high pressure mercury-vapour lamp $(\lambda<380 \mathrm{~nm})$ is a light source. It is well known that the adsorption and degradation of methylene blue in aqueous solution by the catalyst take place simultaneously. Hence, the effect of aqueous $\mathrm{pH}$ on the adsorption and degradation of methylene blue was investigated at the $\mathrm{pH}$ values of $3,8.2$, and 12 , respectively. Then, the percentage degradation of dye was calculated using the following equation:

$$
\text { Percentage Degradation }(\%)=\left[\frac{\left(A_{0}-A\right)}{A_{0}}\right] \times 100 \text {, }
$$



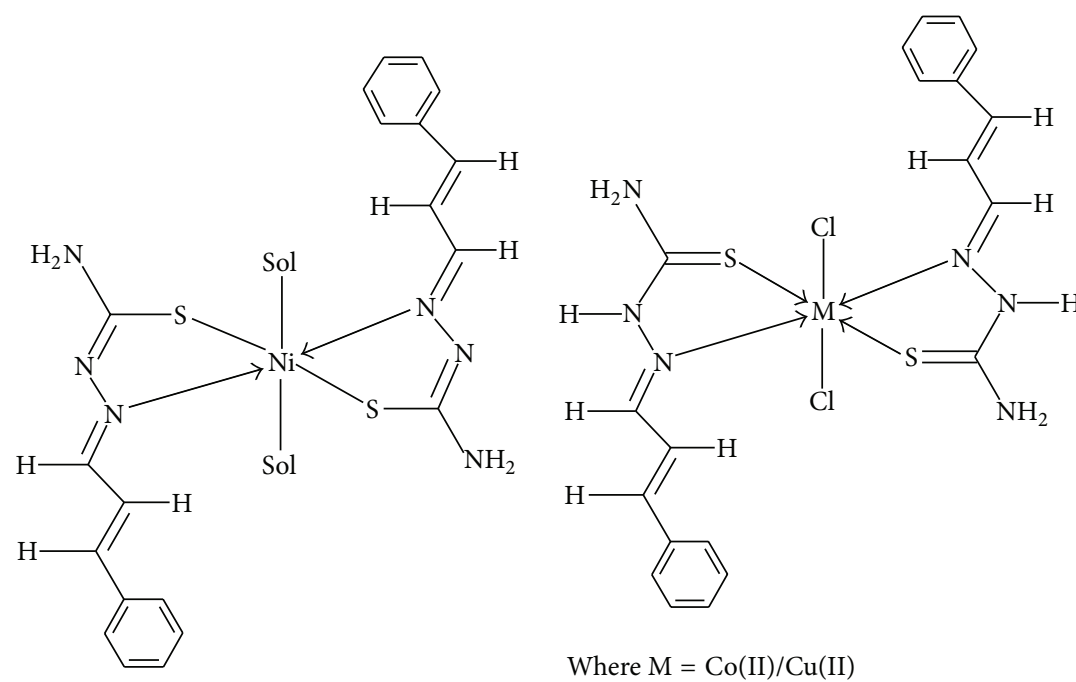

Where $\mathrm{M}=\mathrm{Co}(\mathrm{II}) / \mathrm{Cu}(\mathrm{II})$

FIgURE 2: Tentative structures of copper(II), Ni(II), and Co(II) complexes.

where $A_{0}$ and $A$ are the initial and final concentration of the dye. The initial and final concentration of the dye were measured at regular intervals using a UV-visible spectrophotometer.

\section{Results and Discussion}

3.1. Analytical Data and Magnetic Moments. All the three complexes were found to be air stable and readily soluble in aprotic solvents such as DMF and DMSO due to the substituted groups which increase repulsion and thereby reduce the aggregation of molecules. The solubility decreases in strongly polar solvents such as methanol, ethanol, and water because the alkyl groups and other substituted groups are lipophilic and weakly polar [22]. The conductivity data suggest nonelectrolytic nature of complexes [23]. Room temperature magnetic moment data (Table 1) of the complexes suggest that the complexes were monomeric in nature and that the metal-metal interaction was absent.

3.2. Infrared Spectra. The IR spectra of the complexes are compared with the ligand spectra. Important infrared spectral data and their tentative assignments are presented in Table 2. The band assigned to $(\mathrm{C}=\mathrm{N})$ at $1621 \mathrm{~cm}^{-1}$ in the spectrum of the ligand shifts to $1567-1615 \mathrm{~cm}^{-1}$ in the spectra of complexes suggesting coordination of the imine nitrogen. Coordination of azomethine nitrogen is confirmed with the presence of new band at $355-443 \mathrm{~cm}^{-1}$, assignable to $(\mathrm{M}-\mathrm{N})$ $[24,25]$. The IR spectrum of free ligand exhibits a medium band at $3153 \mathrm{~cm}^{-1}$, which is assigned to $(\mathrm{N}-\mathrm{H})$ vibration. The absence of $(\mathrm{N}-\mathrm{H})$ band in the spectrum of complex provides a strong evidence for the ligand coordination around metal ion in its deprotonated form in nickel complex (except for copper and cobalt complexes). The absorption attributed to $(\mathrm{C}=\mathrm{S})$ at $1178 \mathrm{~cm}^{-1}$ in the spectra of the free ligand shifts to $1159 \mathrm{~cm}^{-1}$ in the spectra of the copper complex, indicating coordination through a thioketonic sulphur, whereas in $\mathrm{Ni}(\mathrm{II})$ complex the disappearance of $(\mathrm{C}=\mathrm{S})$ and the presence of new band at $677 \mathrm{~cm}^{-1}$ indicate the coordination of thiolate sulphur [26] and also the presence of $(\mathrm{M}-\mathrm{S})$ band at $472 \mathrm{~cm}^{-1}[27,28]$.

3.3. Electronic Spectra. The electronic spectra of the complexes are recorded in DMSO solvent and are given in Table 1. The electronic spectra of copper complex show charge transfer bands in high energy region and $\mathrm{d}-\mathrm{d}$ bands in low energy region. The $\mathrm{d}-\mathrm{d}$ band is assigned to ${ }^{2} \mathrm{E}_{\mathrm{g}} \rightarrow{ }^{2} \mathrm{~T}_{2 \mathrm{~g}}$ transition suggesting distorted octahedral structure with moderate Jahn-Teller effect. But in the case of nickel(II) and cobalt(II) complexes, three bands are observed. These bands are assigned to the following transitions in the favour of octahedral structure:

$$
\begin{aligned}
& \text { for Nickel(II) complex: }{ }^{3} \mathrm{~A}_{2 \mathrm{~g}}(\mathrm{~F}) \rightarrow{ }^{3} \mathrm{~T}_{1 \mathrm{~g}}(\mathrm{~F}), \\
& { }^{3} \mathrm{~A}_{2 \mathrm{~g}}(\mathrm{~F}) \rightarrow{ }^{3} \mathrm{~T}_{1 \mathrm{~g}}(\mathrm{~F}) \text { and } \mathrm{A}_{2 \mathrm{~g}}(\mathrm{~F}) \rightarrow{ }^{3} \mathrm{~T}_{1 \mathrm{~g}}(\mathrm{~F}), \\
& \text { for } \mathrm{Co}(\mathrm{II}) \text { complex: }{ }^{4} \mathrm{~T}_{1 \mathrm{~g}} \rightarrow{ }^{4} \mathrm{~T}_{2 \mathrm{~g}},{ }^{4} \mathrm{~T}_{1 \mathrm{~g}}(\mathrm{~F}) \rightarrow \\
& { }^{4} \mathrm{~A}_{2 \mathrm{~g}}(\mathrm{~F}) \text { and }{ }^{4} \mathrm{~T}_{1 \mathrm{~g}}(\mathrm{~F}) \rightarrow{ }^{4} \mathrm{~T}_{1 \mathrm{~g}}(\mathrm{P}) .
\end{aligned}
$$

Based on the analytical data and spectral data, tentative structures of the complexes are shown in Figure 2.

3.4. Photocatalytic Activity of Metal Complexes. The activities of the catalysts were evaluated in the photodegradation of $\mathrm{MB}$ at room temperature. $100 \mathrm{mg}$ of MC was added into $100 \mathrm{~mL}$ of aqueous $\mathrm{MB}$ solution $(5 \mathrm{mg} / \mathrm{L})$, and the solution was stirred for about $15 \mathrm{~min}$. The solution was then exposed to UV light at a distance of $4-5 \mathrm{~cm}$ between the liquid surface and the lamp. The solution kept stirring during irradiations. Photocatalytic degradation using different MCs viz copper, nickel, and cobalt complexes was studied (Figure 3). Experimental results show that copper complex shows maximum degradation at $12 \mathrm{pH}$ (Figure 4). The observed high photocatalytic activity is awkward due to the delocalization of electrons in the conjugated MC as the photocatalytic effect depends on the enhancement in electron-hole $\left(\mathrm{e}^{-} / \mathrm{h}^{+}\right)$separation [29]. 


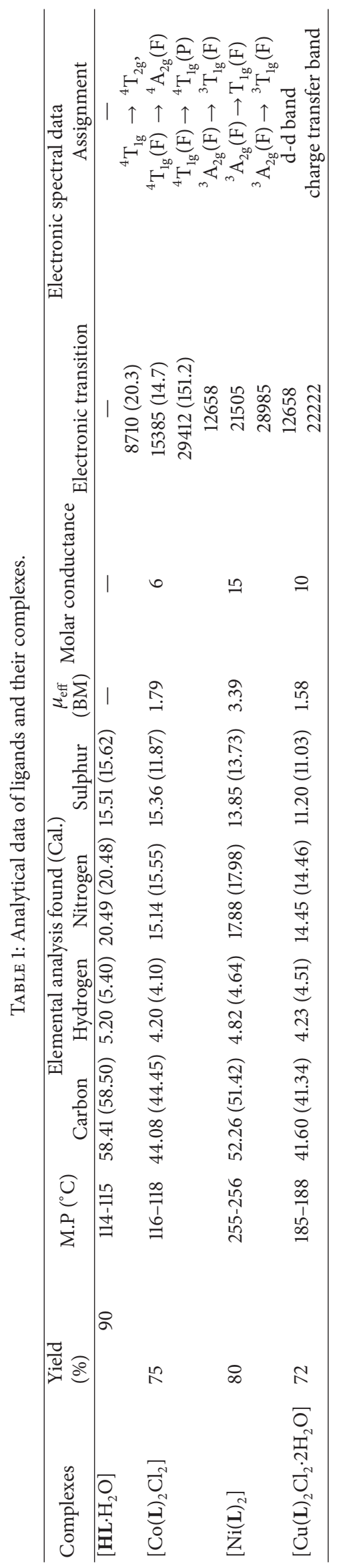


TABLE 2: Infrared vibrational bands $\left(\mathrm{cm}^{-1}\right)$ of ligands and their complexes with tentative assignment.

\begin{tabular}{lcccccc}
\hline Ligand/complex & $v\left(\mathrm{NH}_{2}\right)$ & $v(\mathrm{NH})$ & $v(\mathrm{C}=\mathrm{N})$ & $v(\mathrm{C}=\mathrm{S})$ & $v(\mathrm{C}-\mathrm{S})$ & $v(\mathrm{M}-\mathrm{N})$ \\
\hline $\mathrm{HL} \cdot \mathrm{H}_{2} \mathrm{O}$ & $3417(\mathrm{br}), 3261(\mathrm{~s})$ & $3153(\mathrm{br})$ & $1621(\mathrm{br})$ & $1178(\mathrm{~s})$ & - & - \\
{$\left[\mathrm{Co}(\mathrm{L})_{2} \mathrm{Cl}_{2}\right]$} & $3416(\mathrm{br}), 3261(\mathrm{~s})$ & $3154(\mathrm{br})$ & $1610(\mathrm{br})$ & - & - & $443(\mathrm{~s})$ \\
{$\left[\mathrm{Ni}(\mathrm{L})_{2}\right]$} & $3426(\mathrm{br}), 3228(\mathrm{~s})$ & - & $1567(\mathrm{~s})$ & - & 677 & $355(\mathrm{~s})$ \\
{$\left[\mathrm{Cu}(\mathrm{L})_{2} \mathrm{Cl}_{2} \cdot 2 \mathrm{H}_{2} \mathrm{O}\right]$} & $3463(\mathrm{br}), 3211(\mathrm{~s})$ & $3050(\mathrm{br})$ & $1615(\mathrm{br})$ & $1159(\mathrm{~s})$ & - & - \\
\hline
\end{tabular}

TAble 3: Decolorization of dyes using $\mathrm{Cu}(\mathrm{II}), \mathrm{Ni}(\mathrm{II})$, and Co(II) complexes.

\begin{tabular}{|c|c|c|c|c|c|c|}
\hline \multirow{2}{*}{$\begin{array}{l}\text { Dye/metal complex } \\
(5 \mathrm{mg})\end{array}$} & \multicolumn{3}{|c|}{$\%$ of removal at pH's without UV } & \multicolumn{3}{|c|}{$\%$ of removal at pH's with UV } \\
\hline & 3.0 & 8.2 & 12.0 & 3.0 & 8.2 & 12.0 \\
\hline Methylene blue & No change & 13.82 & 24.0 & 5.69 & 29.93 & 47.73 \\
\hline $\mathrm{Co}(\mathbf{L})_{2} \mathrm{Cl}_{2}$ & 14.78 & 14.78 & 44.66 & 9.24 & 9.24 & 83.07 \\
\hline $\mathrm{Ni}(\mathbf{L})_{2}$ & 7.9 & 29.93 & 35.72 & 38.8 & 22.18 & 80.44 \\
\hline $\mathrm{Cu}(\mathbf{L})_{2} \mathrm{Cl}_{2} \cdot 2 \mathrm{H}_{2} \mathrm{O}$ & 33.92 & 8.83 & 33.44 & 43.33 & 3.3 & 88.80 \\
\hline
\end{tabular}

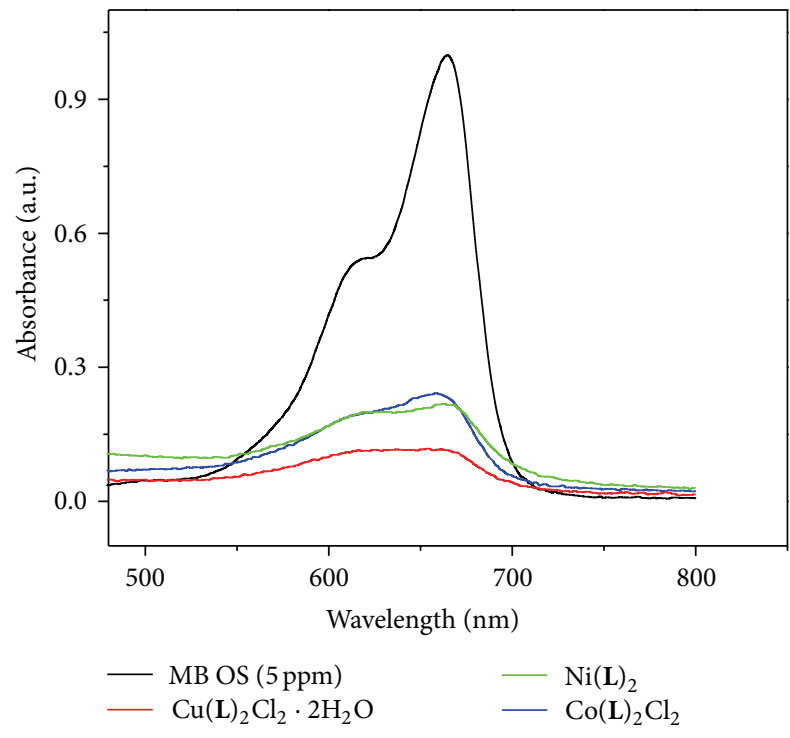

FIGURE 3: Degradation of methylene blue under UV light.

3.4.1. The Effect of Solution $p H$. The effect of $\mathrm{pH}$ on the adsorption of methylene blue on metal complex has been studied by selecting the pHs 3, 8.2, and 12 . The results are summarized in Table 3 . In general, the photochemical degradation depends strongly on the $\mathrm{pH}$ of the reaction medium and the same is observed in the present study. The uptake of methylene blue increased rapidly with the increase of $\mathrm{pH}$. The dye degradation is more favorable at higher $\mathrm{pH}$ condition due to the formation of more $\mathrm{OH}$ radicals, which will be utilized for oxidative degradation of methyl blue. A similar investigation reported that the adsorption of dye increased by increasing the solution $\mathrm{pH}$ [7].

Mechanism. Metal complex system produced hydroxyl radicals during the catalytic reaction. This is not surprising, since

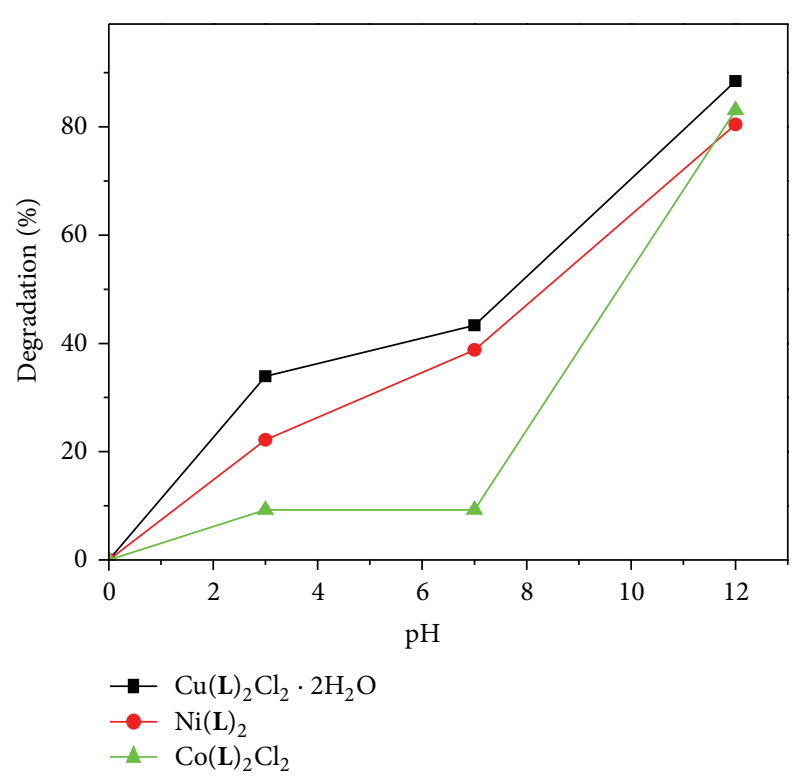

FIGURE 4: \% degradation of methylene blue at different $\mathrm{pH}$ conditions.

the production of - $\mathrm{OH}$ was already confirmed in other metalbased AOP systems $[17,30]$. The radicals are strong oxidizing agents that react with dyes and cause their decolorization. The tentative mechanism has been proposed for the degradation of methylene blue in the presence of copper, nickel, and cobalt complexes and light (Figure 5).

Consider

$$
\begin{gathered}
{[\mathrm{MLn}]+\text { Light } \longrightarrow[\mathrm{MLn}]^{*}+{ }^{3} \mathrm{O}_{2} \longrightarrow \mathrm{OH}^{\bullet}} \\
\mathrm{OH}^{\bullet}+\text { Dye } \longrightarrow \text { Oxidative products }
\end{gathered}
$$

( $\mathrm{M}$ stands for copper, nickel, and cobalt). 


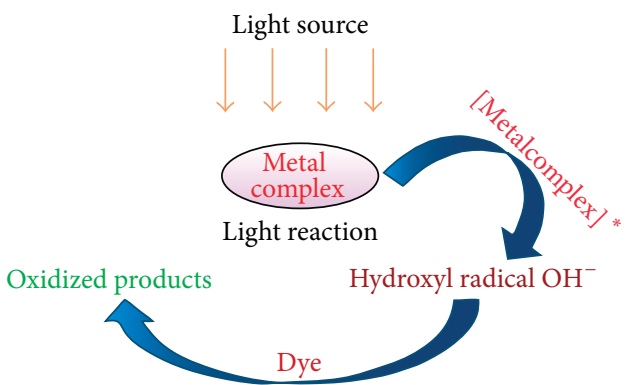

FIgURE 5: Photodegradation mechanism of metal complex.

\section{Conclusions}

$\mathrm{Co}(\mathrm{II}), \mathrm{Ni}(\mathrm{II})$, and $\mathrm{Cu}(\mathrm{II})$ complexes of $(2 E)-2-[(2 E)-3-$ phenylprop-2-en-1-ylidene]hydrazinecarbothioamide (HL) are synthesized and characterized based on the various spectroscopic techniques. The rate of photocatalytic degradation of methylene blue using prepared metal complexes was successfully carried out under UV light. The increasing order of the rate with different metal complexes is as follows: $\mathrm{Cu}$ (II) $>\mathrm{Co}$ (III) $>\mathrm{Ni}$ (II). The generation of the hydroxyl radical is responsible for the degradation of dye photocatalytically. The dye has been successfully degraded $88.8 \%$ in the presence of copper complex in UV light at $\mathrm{pH}$ 12.

\section{Conflict of Interests}

The authors declare that they have no conflict of interests.

\section{Acknowledgments}

The authors are thankful to Visvesvaraya Technological University, Belgaum, for financial support (VTU/Aca./2010-11/A9/13261 dated January 17, 2011) and M. S. Ramaiah Institute of Technology, Bangalore, for providing facilities.

\section{References}

[1] V. J. Inglezakis and S. G. Poulopoulos, AdsorptIon, Ion Exchange and Catalysis: Design of operatIons and Environmental applicatIons, Elsevier, 2006.

[2] E. Forgacs, T. Cserháti, and G. Oros, "Removal of synthetic dyes from wastewaters: a review," Environment International, vol. 30, no. 7, pp. 953-971, 2004.

[3] S. Naghiloo, A. Habibi-Yangjeh, and M. Behboudnia, "Adsorption and photocatalytic degradation of methylene blue on $\mathrm{Zn}_{1-x} \mathrm{Cu}_{x} \mathrm{~S}$ nanoparticles prepared by a simple green method," Applied Surface Science, vol. 257, no. 6, pp. 2361-2366, 2011.

[4] A. B. Prevot, C. Baiocchi, M. C. Brussino et al., "Photocatalytic degradation of Acid Blue 80 in aqueous solutions containing $\mathrm{TiO}_{2}$ suspensions," Environmental Science and Technology, vol. 35, no. 5, pp. 971-976, 2001.

[5] B. Neppolian, H. C. Choi, S. Sakthivel, B. Arabindoo, and V. Murugesan, "Solar light induced and $\mathrm{TiO}_{2}$ assisted degradation of textile dye reactive blue 4," Chemosphere, vol. 46, no. 8, pp. 1173-1181, 2002.
[6] R. M. Christie, Colour Chemistry, Royal Society of Chemistry Paperbacks, 2001.

[7] S. Lodha, A. Jain, V. K. Sharma, and P. B. Punjabi, "Photocatalytic degradation of rhodamin-b using metal complexes and hydrogen peroxide," Indonesian Journal Chemistry, vol. 42, pp. 42-46, 2008.

[8] A. R. Khataee and M. B. Kasiri, "Photocatalytic degradation of organic dyes in the presence of nanostructured titanium dioxide: influence of the chemical structure of dyes," Journal of Molecular Catalysis A, vol. 328, no. 1-2, pp. 8-26, 2010.

[9] A. Kajbafvala, H. Ghorbani, A. Paravar, J. P. Samberg, E. Kajbafvala, and S. K. Sadrnezhaad, "Effects of morphology on photocatalytic performance of Zinc oxide nanostructures synthesized by rapid microwave irradiation methods," Superlattices and Microstructures, vol. 51, no. 4, pp. 512-522, 2012.

[10] W. G. Kuo, "Decolorizing dye wastewater with Fenton's reagent," Water Research, vol. 26, no. 7, pp. 881-886, 1992.

[11] D. F. Ollis and H. Al-Akabi, Photocatalytic Purification and Treatment of Water and Air, Elsevier, Amsterdam, The Netherlands, 1993.

[12] I. Arslan and I. A. Balcioglu, "Degradation of commercial reactive dyestuffs by heterogenous and homogenous advanced oxidation processes: a comparative study," Dyes and Pigments, vol. 43, no. 2, pp. 95-108, 1999.

[13] I. Arslan, I. A. Balcioğlu, and D. W. Bahnemann, "Advanced chemical oxidation of reactive dyes in simulated dyehouse effluents by ferrioxalate-Fenton/UV-A and $\mathrm{TiO}_{2} / \mathrm{UV}$-A processes," Dyes and Pigments, vol. 47, no. 3, pp. 207-218, 2000.

[14] F. Herrera, J. Kiwi, A. Lopez, and V. Nadtochenko, "Photochemical decoloration of Remazol Brilliant Blue and Uniblue A in the presence of $\mathrm{Fe}^{3+}$ and $\mathrm{H}_{2} \mathrm{O}_{2}$, Environmental Science and Technology, vol. 33, no. 18, pp. 3145-3151, 1999.

[15] K. H. Gregor, "Oxidative decolorization of textile waste with advanced oxidation processes," in Chemical Oxidation: Technologies for Nineties, W. W. Eckendfelder, A. R. Bowers, and J. A. Roth, Eds., pp. 161-193, 1992.

[16] F. Nerud, P. Baldrian, J. Gabriel, and D. Ogbeifun, "Decolorization of synthetic dyes by the Fenton reagent and the $\mathrm{Cu} /$ pyridine $/ \mathrm{H}_{2} \mathrm{O}_{2}$ system," Chemosphere, vol. 44, no. 5, pp. 957-961, 2001.

[17] P. Verma, P. Baldrian, and F. Nerud, "Decolorization of structurally different synthetic dyes using cobalt(II)/ascorbic acid/hydrogen peroxide system," Chemosphere, vol. 50, no. 8, pp. 975-979, 2003.

[18] T. Watanabe, K. Koller, and K. Messner, "Copper-dependent depolymerization of lignin in the presence of fungal metabolite, pyridine," Journal of Biotechnology, vol. 62, no. 3, pp. 221-230, 1998.

[19] J. Gabriel, V. Shah, K. Nesměrák, P. Baldrian, and F. Nerud, "Degradation of polycyclic aromatic hydrocarbons by the copper(II)-hydrogen peroxide system," Folia Microbiologica, vol. 45 , no. 6 , pp. $573-575,2000$.

[20] I. A. Salem, "Kinetics of the oxidative color removal and degradation of bromophenol blue with hydrogen peroxide catalyzed by copper(II)-supported alumina and zirconia," Applied Catalysis B, vol. 28, no. 3-4, pp. 153-162, 2000.

[21] P. Murali Krishna, K. Hussain Reddy, J. P. Pandey, and D. Siddavattam, "Synthesis, characterization, DNA binding and nuclease activity of binuclear copper(II) complexes of cuminaldehyde thiosemicarbazones," Transition Metal Chemistry, vol. 33, no. 5, pp. 661-668, 2008. 
[22] Z. Chen, Y. Wu, D. Gu, and F. Gan, "Nickel(II) and copper(II) complexes containing 2-(2-(5-substitued isoxazol3-yl)hydrazono)-5,5-dimethylcyclohexane-1,3-dione ligands: synthesis, spectral and thermal characterizations," Dyes and Pigments, vol. 76, no. 3, pp. 624-631, 2008.

[23] H. H. Willard, L. L. Merritt, J. A. Dean, and F. A. Settle, Instrumental Methods of Chemical Analysis, C.B.S. Publishers, 1986.

[24] V. Suni, M. R. P. Kurup, and M. Nethaji, "Structural and spectral investigations on some new $\mathrm{Ni}(\mathrm{II})$ complexes of di-2-pyridyl ketone N(4)-phenylthiosemicarbazone," Polyhedron, vol. 26, no. 13, pp. 3097-3102, 2007.

[25] D. X. West, A. A. Nassar, F. A. El-Saied, and M. I. Ayad, "Nickel(II) complexes of 2-aminoacetophenone N(4)-substituted thiosemicarbazones," Transition Metal Chemistry, vol. 23, no. 4, pp. 423-427, 1998.

[26] K. Alomar, A. Landreau, M. Kempf, M. A. Khan, M. Allain, and G. Bouet, "Synthesis, crystal structure, characterization of zinc(II), cadmium(II) complexes with 3-thiophene aldehyde thiosemicarbazone (3TTSCH). Biological activities of 3TTSCH and its complexes," Journal of Inorganic Biochemistry, vol. 104, no. 4, pp. 397-404, 2010.

[27] K. Nag and D. S. Joarder, "Metal complexes of sulfurnitrogen chelating agents. V. 2-N-Ethylaminocyclopentene-1dithiocarboxylic acid complexes of $\mathrm{Ni}(\mathrm{II}), \mathrm{Pd}(\mathrm{II}), \mathrm{Pt}(\mathrm{II}), \mathrm{Co}(\mathrm{II})$, $\mathrm{Co}(\mathrm{III})$, and $\mathrm{Cu}(\mathrm{I})$," Canadian Journal of Chemistry, vol. 54, pp. 2827-2831, 1976.

[28] R. Roy, M. Chaudhury, S. K. Mondal, and K. Nag, "Metal complexes of sulphur-nitrogen chelating agents. Part 11: synthesis, characterisation, and thermodynamics of nucleophilic substitution reactions of monohalogeno nickel(II) complexes of tridentate ligands of the type SNN in solution and the solid state," Journal of the Chemical Society, Dalton Transactions, no. 8, pp. 1681-1686, 1984.

[29] K. K. Senapati, C. Borgohain, K. C. Sarma, and P. Phukan, "Photocatalytic degradation of methylene blue in water using $\mathrm{CoFe} 2 \mathrm{O}_{4}-\mathrm{Cr}_{2} \mathrm{O}_{3}-\mathrm{SiO}_{2}$ fluorescent magnetic nanocomposite," Journal of Molecular Catalysis A, vol. 346, no. 1-2, pp. 111-116, 2011.

[30] G. Tabbì, S. C. Fry, and R. P. Bonomo, "ESR study of the non-enzymic scission of xyloglucan by an ascorbate- $\mathrm{H}_{2} \mathrm{O}_{2}$ copper system: the involvement of the hydroxyl radical and the degradation of ascorbate," Journal of Inorganic Biochemistry, vol. 84, no. 3-4, pp. 179-187, 2001. 

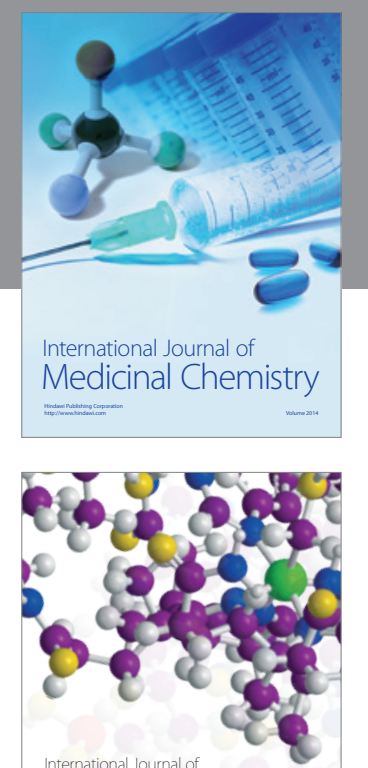

\section{Carbohydrate} Chemistry

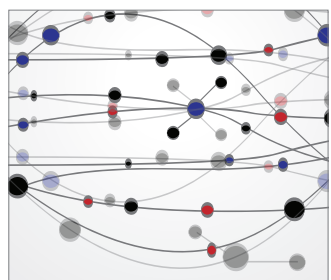

The Scientific World Journal
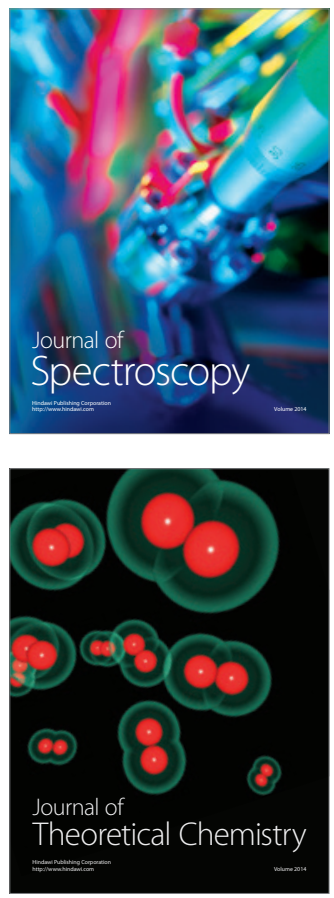
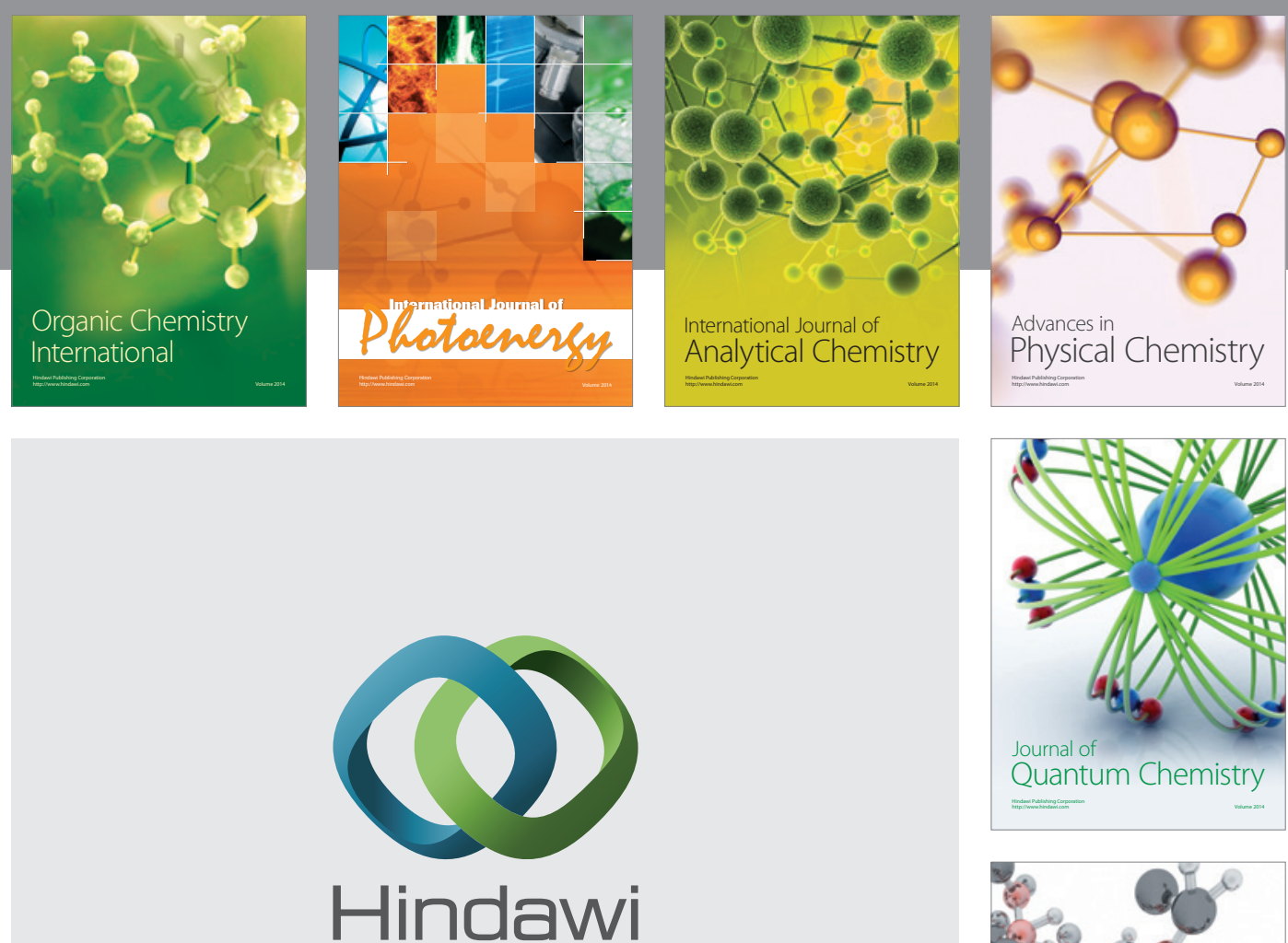

Submit your manuscripts at

http://www.hindawi.com

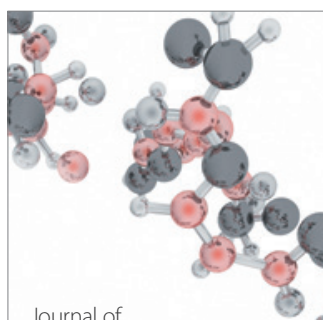

Analytical Methods

in Chemistry

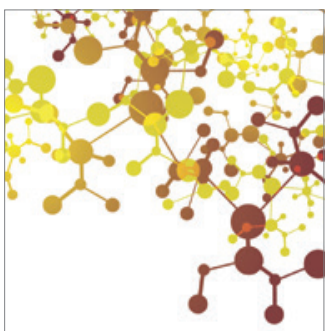

Journal of

Applied Chemistry

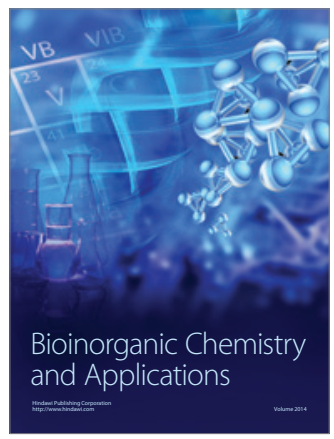

Inorganic Chemistry
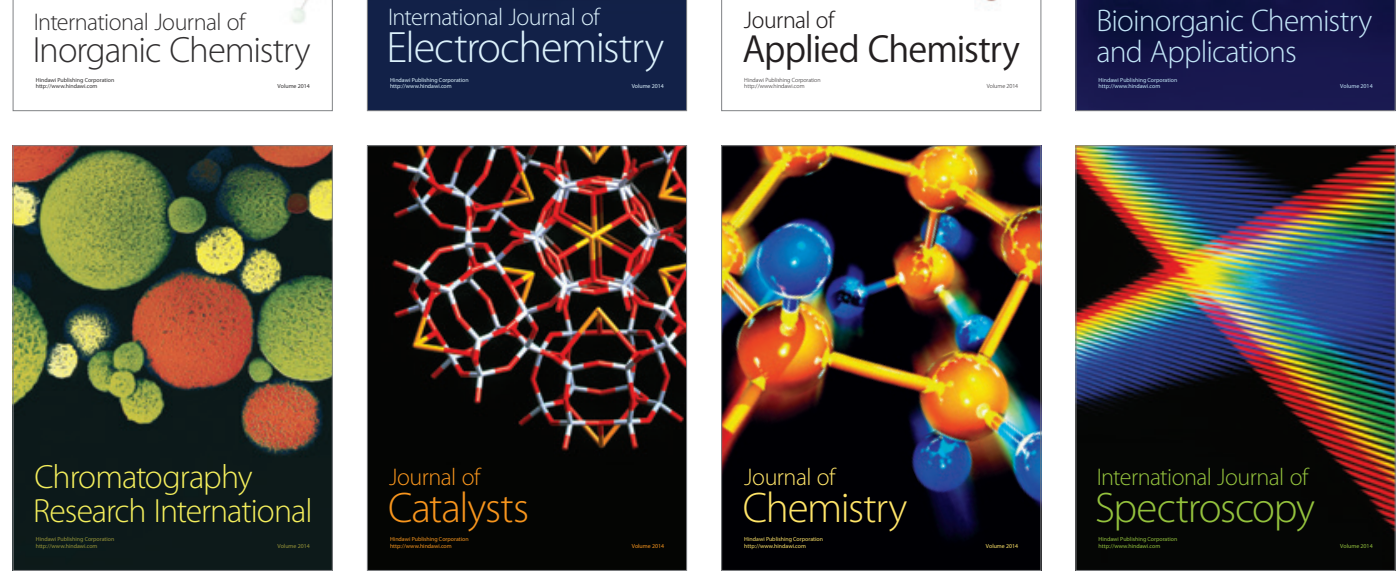